\title{
Desde la justicia al abordaje historiográfico: los expedientes judiciales-criminales decimonónicos del Archivo Nacional Histórico*
}

\author{
From justice to historiographical approach: nineteenth-century criminal \\ court records of the Chilean Historical National Archive
}

\author{
Víctor Mauricio Brangier Peñailillo \\ vmbrangi@gmail.com \\ Investigador y Académico \\ Centro de Estudios Históricos, Universidad Bernardo O 'Higgins \\ Calle Fábrica 1990, Boulevard Universidad Bernardo O 'Higgins, segundo piso \\ Comuna de Santiago - Santiago \\ Chile \\ Germán Adolfo Morong Reyes \\ gmorongreyes@yahoo.es \\ Investigador y Académico \\ Centro de Estudios Históricos, Universidad Bernardo O 'Higgins \\ Calle Fábrica 1990, Boulevard Universidad Bernardo O 'Higgins, segundo piso \\ Comuna de Santiago - Santiago \\ Chile
}

\section{Resumen}

El artículo examina las formas en que la historiografía chilena de las tres últimas décadas ha abordado el valor testimonial presente en los expedientes judiciales criminales, elaborados en el siglo XIX y almacenados en el Archivo Nacional Histórico. El estudio tiene como objetivos analizar las dinámicas históricas que convergieron en la fabricación del documento, en la estructuración de un material fragmentario y mediado, deduciendo por tanto, los desafíos en su utilización como fuente primaria. Luego, se pretende evaluar la pertinencia de metodologías centradas en aquellas condiciones de posibilidad, rescatando el potencial heurístico de "lecturas a contrapelo" y de enfoques "culturalistas" que permitan enfrentar el fenómeno de la mediación escritural entre testimonio y expediente. El diagnóstico sobre el grado de asimilación que ha tenido la historiografía nacional respecto de estos enfoques permite concluir la serie de tareas pendientes en la problematización y hermenéutica de una documentación de uso creciente.

\section{Palabras claves}

Archivo; Historiografía; Enfoque cultural.

\begin{abstract}
This article examines the ways in which Chilean historiography has addressed, in the last three decades, the issue of evidential value in the judicial criminal records made in the 19th century and stored in the National Historical Archive. The study aims to analyze the historical dynamics that converged in the manufacture of documents, in structuring a fragmentary and mediated material, thus deducing the challenges of using them as a primary source. Therefore, it provides an assessment of the relevance of methodologies focused on those conditions of possibility, rescuing the heuristic potential of "reading against the grain" and "culturalist" approaches able to address the phenomenon of scriptural mediation between witness and record. The diagnosis of the assimilation that national historiography has had on these approaches allows us to conclude the number of outstanding tasks on the problematization and hermeneutics over this documentation of increased use.
\end{abstract}

\section{Keywords}

Archive; Historiography; Cultural approach.

Recibido el: 11/2/2016

Aceptado el: 27/7/2016

\footnotetext{
* El estudio es parte integrante de una tesis doctoral inédita, relativa a las "culturas jurídico-judiciales" y a los "usos sociales" presentes en la justicia criminal de la zona centro sur de Chile, entre 1824 y 1875 . El contenido del artículo conformó el análisis introductorio sobre la materia prima central de la obra: un cuerpo de 411 expedientes judiciales por conflictos interpersonales, incoados por iniciativa de parte y donde se disputaban intereses de alto valor para los litigantes, como la vida, la honra, la propiedad agro-ganadera y la paz en el vecindario. El estudio doctoral contó con el patrocinio de la Beca para Estudios de Doctorado en Chile, a cargo de la Comisión Nacional de Investigación Científica y Tecnológica (CONICET) entre los años 2010 y 2014.
} 
Durante las últimas tres décadas, la historiografía en Chile ha ido utilizando con mayor frecuencia e intensidad los expedientes judiciales como materia prima. Este proceso ha sido abonado por las corrientes de la Historia Social occidental que, desde la segunda mitad del siglo XX "re-descubrieron" este material abundante en los archivos para alimentar los lineamientos centrales de una History from below. El enfoque ganó terreno rápidamente en América Latina y Chile no fue la excepción, como se detallará a lo largo de estas páginas. Desde fines de la década de 1980, y tras el cese de la dictadura cívico-militar, los estudios históricos se volcaron fundamentalmente hacia la "Historia social del bajo pueblo". Desde entonces, se produjo una orientación de las ciencias sociales y humanidades nacionales a nutrir una memoria social y de ese modo, superar los efectos amnésicos de la política de estado autoritario, concentrada en el olvido de proyectos políticos populares en el pasado. También ha contribuido a esta valoración del documento judicial, la existencia de un material generoso en el Archivo Nacional Histórico de Santiago [en adelante ANH], con una catalogación certera y de permanente incremento en la cobertura de piezas y legajos para facilitar su consulta pública.

Desde 1930, el ANH almacena expedientes judiciales inéditos, con la promulgación en noviembre del año anterior de la ley que dio a luz a la Dirección General de Bibliotecas, Archivos y Museos. El artículo $14^{\circ}$ de esta normativa explicaba que al ANH debían ingresar anualmente "los libros copiadores de sentencia de los Tribunales de Justicia y los expedientes judiciales que hayan cumplido ochenta años de antigüedad". De todos modos, la constitución de los expedientes judiciales como material de archivo, había comenzado antes, pues por ley de 15 de octubre de 1875 se dio nacimiento a los archivos judiciales de Santiago y de Valparaíso (ANH 2009, p. 14). El ANH, por tanto, se constituye en la actualidad en el principal repositorio nacional de expedientes judiciales confeccionados antes de 1900. Los contiene

en los archivos pertenecientes a cada juzgado de Letras del siglo XIX. Estos fondos están presentados por un catálogo que divide el material en causas civiles y criminales. Además, los ordena cronológicamente y de acuerdo a la materia jurídica que dio origen al juicio, según figura transcrito en la carátula de cada unidad.

El uso sistemático de esta documentación obliga a hacer un alto en el camino para reflexionar sobre los desafíos metodológicos que presenta, los enfoques utilizados para enfrentar sus testimonios y las oportunidades que ofrece la misma fuente para capitalizar su especificidad entre las otras categorías de fuentes primarias. La historiografía nacional ha puesto atención particular en aquellos expedientes que, a primera vista, permitirían acceder a las voces de actores sociales silenciados por los relatos historiográficos tradicionales y por documentación más oficial. La profusión de trabajos monográficos se ha centrado en declaraciones de inculpados, de testigos, en los autos de querellas y denuncias presentes en sumarios. Por tanto, han sido los expedientes nacidos de juicios criminales los que han capturado con mayor efectividad los esfuerzos investigativos. Han recibido un tratamiento mayoritario debido a que satisfarían 
las expectativas de la historia social del bajo pueblo por dar cuenta de historias de lucha y gestión social ante los embates del poder y sus aparatos policiales y de criminalización social. En este sentido, los estudios se han concentrado en el proceso histórico de incremento en la voluntad de intervención estatal experimentado entre las reformas borbónicas del siglo XVIII y la construcción de estado independiente desde la década de 1830, con supresión de las soberanías locales y las culturas populares. ${ }^{1}$

Tomando en consideración este escenario, en estas páginas se ha planteado como objetivo el análisis de los desafíos que plantean hacia la historiografía nacional, los testimonios inscritos en los expedientes judiciales-criminales tramitados en el siglo XIX y almacenados en el ANH. Este propósito se ha diseñado, considerando que la documentación fue fruto de una práctica judicial socialmente localizada y mediada por un ejercicio escritural especializado en la traducción de los testimonios de litigantes y de testigos. Complementariamente, el artículo se propone examinar la utilidad de metodologías aplicadas en investigaciones sobre material similar en historiografías de otras latitudes y que han problematizado el valor informativo de los testimonios de los expedientes. De ese modo, y como tercer objetivo, se apunta a diagnosticar el impacto que han tenido estas metodologías en los abordajes sobre esta documentación en Chile.

\section{Expedientes judiciales de archivo: esquirlas de justicia, de conflictos y de mediaciones}

En la administración de justicia criminal del siglo XIX, la práctica de los juzgados generaba un registro escritural heterogéneo, discontinuo y muchas veces inconcluso. La serie de variables que influían en la fabricación de la documentación dio como resultado la existencia de un cuerpo documental diverso en extremo que atestigua el grado de especificidad presente en cada situación judicial a la hora de poner por escrito las fases de las causas. Cada escalafón del organigrama de autoridades con potestad de juzgar podía generar documentos. Así lo hacían los inspectores, jueces instalados en las bases de la pirámide y los subdelegados, quienes, por lo general, recibían las querellas y denuncias y efectuaban la investigación sumaria poniendo por escrito sus resultados. Los mismos alcaldes o regidores de municipio, actuando como jueces "legos" de primera instancia, reproducían el ejercicio cuando las partes concurrían a sus despachos o la gravedad de los hechos les conminaba a actuar por iniciativa propia o "de oficio".2 La situación escritural se complejizaba cuando estos magistrados recibían los sumarios de aquellos jueces subalternos

\footnotetext{
${ }^{1}$ El listado de esta discusión historiográfica es extenso, pero sirva de muestra los trabajos chilenos presentes en la obra colectiva editada por Ernesto Boholavsky y Milton Godoy (2010).

2 El Reglamento de Administración de Justicia promulgado en 1824 sirvió como marco normativo provisorio para la organización de juzgados, tribunales y de atribuciones de los jueces hasta 1875, cuando salió a la luz la ley orgánica al respecto. El Reglamento estipulaba que en las ocho provincias existentes en el territorio nacional, debía operar un juez de Letras en cada Departamento (las unidades administrativas en que se dividían las provincias). Pero señalaba que en caso que se careciera de jueces de este tipo, le subrogaría "indefinidamente" el alcalde de la villa cabecera departamental. Por su parte, la justicia de menor y de mínima cuantía, en las subdelegaciones y distritos, estarían a cargo respectivamente de los subdelegados e inspectores, autoridades gubernativas y policiales dependientes del Gobernador departamental (ANGUITA 1913 , p. 152-163).
} 
y debían continuar la causa, agregando, corrigiendo o devolviendo escritos mal tramitados. En muchas ocasiones, estos jueces actuaban en forma verbal, llegando a acuerdos con las partes de los que no quedaba evidencia más que el carácter inconcluso de la tramitación que finalizaba en un punto intermedio del juicio. De ese modo, y como lo requería el Reglamento de Administración de Justicia de 1824, cada uno de estos jueces locales debía tener un archivo propio ("un libro a cargo de su respectivo escribano") donde conservar estos trazos marginales de sus prácticas judiciales (ANGUITA 1913, p. 152).

Las visitas judiciales, correspondiente a fiscalizaciones periódicas y en terreno, de jueces de Letras hacia estos jueces "legos", se concentraron en estos archivos precarios y escasos. Tras la revisión de este material, surgieron las principales críticas de la esfera letrada, que subrayó la no conclusión de las causas y se escandalizó por la paralización de juicios que envolvían crímenes graves. Una situación similar deja entrever la serie de reparos que los ministros de las Cortes de Apelaciones hicieron llegar a los jueces de Letras. Los reproches descendían tras la revisión de los informes trimestrales que estos elevaban a tales tribunales dando cuenta del estado en que se encontraban las tramitaciones de las causas dentro de sus órbitas de competencia (BRANGIER 2012, p. 124-151).

La documentación que resguarda el $A N H$, refleja entonces una parte ínfima de la actividad judicial intensa del periodo. Se trata, al fin, de los expedientes que alcanzaron a derivar aquellos jueces "legos" hacia los juzgados de Letras y de los que estos produjeron por iniciativa propia. Pero a su vez, el ANH recibió sólo los registros de juicios que pudieron rescatarse de los archivos de los jueces letrados, los que no gozaban de las condiciones ideales de seguridad para evitar extravíos, hurtos y deterioro por las condiciones laborales y ambientales adversas (PALMA 2014, p. 20). Al fin, el ANH guarda retazos de la judicialización del proceso: no todo el litigio se escribió. Y de lo que se escribió, no todo se conserva.

Por otro lado, estos expedientes judiciales en materia criminal se vinculaban a estelas de conflictos interpersonales que desbordaban con creces las fronteras del juzgado. El juicio en sí se asociaba a esquirlas de discursos, de acuerdos y de pacificaciones previas y simultáneas. Fragmentos de emociones, razonamientos e intereses. Esta condición segmentada del documento se debía, en gran medida, a que la judicialización figuraba como el recorte de un conflicto más largo que tuvo lugar fuera del juzgado. Precedido, acompañado y sucedido por el plexo de las tensiones sociales, el acto de asistir ante la autoridad con potestad judicial apuntaba a la reformulación de la trama compleja que sostenía al conflicto interpersonal (UNDURRAGA 2015, p. 1-2).

La incardinación de la potestad de juzgar que portaban las autoridades gubernativas locales, en el seno de las relaciones sociales, satisfacía las expectativas sobre la función de la justicia, desde el periodo de construcción de estado independiente, heredadas de la cultura jurídica y política de la monarquía ibérica y sus posesiones de ultramar. Como ha precisado la historia crítica del derecho, las metrópolis de España y Portugal reinaron sobre suelo americano a partir de la delegación de la potestad de juzgar en la gama de funcionarios que gobernaban en su nombre, quienes debían, sobre todo, mantener la paz social 
en comunidades internamente desiguales y con corporaciones celosas de sus fueros y derechos. De ese modo, la justicia se concebía con un fin "redistributivo", manteniendo el orden social establecido, preservando a cada cual en su derecho específico y dándole a cada quien lo que "le correspondiese" (HESPANHA 1993, p. 210; GARRIGA 2004, p. 13-44; AGÜERO 2008, p. 130; BARRIERA 2010, p. 28; DE ARAUJO 2015). Tras las batallas de independencia en Chile, se sucedieron discursos tendientes a resguardar una férrea separación de los poderes del estado, sin embargo, en ningún caso se les arrebató la potestad de juzgar a las autoridades gubernativas, policiales y edilicias locales. La necesidad de mantener "la tranquilidad del vecindario" y el "orden público", junto con el interés escaso de los abogados por fungir como jueces de Letras territoriales (DE RAMÓN 1989, p. 1-59), llevó a las dirigencias nacionales a confiar la función judicial en estos "jueces legos" hasta bien entrado el siglo XIX. ${ }^{3}$

La convicción respecto a que la justicia hispanoamericana debía insertarse en medio del curso del conflicto social para mantener la paz y la "vida en policía" (MARCONI; BARRIERA 2015, p. 148), sumado a la pertenencia de los jueces "legos" al entorno social y cultural en que se desenvolvían los litigantes, generó una práctica judicial cotidiana sin límites precisos con otras esferas sociales de resolución de conflictos, como ha ido demostrándose paulatinamente en la historiografía chilena (SALINAS 2000; ROJAS 2008; MORENO 2015; CELIS 2015). Tal como se sabe para el caso de España desde inicios de la Modernidad, de los tránsitos experimentados por los conflictos sociales y sus respectivos 100 acuerdos, negociaciones y (re)conciliaciones, desde los escenarios informales hacia los juzgados, (KAGAN 1991, p. 41; MANTECÓN 2015), hoy se conoce un poco más respecto a la complejidad de los conflictos sociales interpersonales en Chile en el siglo XIX y el espacio marginal (aunque a veces determinante) que ocupaba la judicialización dentro del conjunto. Por ello, el juicio y los expedientes que de ahí derivaron, se conciben como estelas ínfimas de una red densa de tensiones que conformaban al conflicto y que escapaban del radio judicial, de sus prácticas de escritura y del expediente. Al fin, para sintetizar las dos aristas de la fragmentación que refleja el expediente judicial en relación a los conflictos sociales que pretendía traducir, es posible asentar que el juicio reflejaría un recorte de la realidad y el expediente un recorte del juicio.

Por último, debe considerarse un tercer ángulo respecto a la naturaleza fragmentaria del documento y se vincula al proceso de su fabricación: las fuentes judiciales fueron elaboradas tras un ejercicio insoslayable de mediación. Entre la voz de los sujetos sociales y el resultado escrito de las tramitaciones se encontraba el arte cotidiano de agentes especializados en la escritura judicial. El testimonio de los litigantes, de los testigos y de los reos, por lo general no quedó plasmado directamente en el papel. Hubo un ejercicio de transcripción y de

\footnotetext{
3 El reemplazo de una esfera "lega" por una justicia letrada, fue un proceso institucionalmente muy lento a lo largo de la centuria. Recién en 1888 se dictó la normativa -que no se alcanzaría a cumplir del todo a fines del siglo XIX- que exigía un juez de Letras en cada Departamento que contara con más de 30.000 habitantes (STABILI 2000, p. 238). Además, sólo la ley orgánica de tribunales de 1875 estipuló la separación de funciones gubernativas y judiciales para los cargos de subdelegados e inspectores, creando, paralelos a estos funcionarios, los jueces de subdelegación y de distrito (Estado de Chile 1875, p. 16 y ss.).
} 
traducción por parte de escribanos, representantes especializados, defensores, curadores y hasta del mismo juez. Los historiadores franceses Arlette Farge y Jacques Revel, concibieron esta mediación escritural, respectivamente, como una "práctica específica de poder", que desnudaría las "relaciones de fuerza" vigentes en cada juicio (GALLUCI 2009, p. 3).

A fin de cuentas, los expedientes judiciales criminales del siglo XIX chileno, portan en su integridad una triple fragmentación. Su dispersión constitutiva es el resultado de prácticas discontinuas de escritura judicial, de la inserción del juicio en conflictos sociales complejos y de un doble proceso de mediación: de tipificación técnico-jurídica de las pugnas desarrolladas en la arena social y de traducción de las voces de sus actores a través de la escucha y la escritura de los agentes de los juzgados. La fuente judicial se ofrece en el archivo, a primera vista, como un conjunto mal cosido de retazos que escasamente pueden dar cuenta de las experiencias vividas en los juzgados y sus fronteras sociales. La historiografía en Chile que ha trabajado con este material, ha debido asumir el desafío de cuestionar su valor informativo per se $y$ se ha visto en la obligación de forzar fronteras metodológicas, hurgar en las condiciones de posibilidad del documento y cautelar las conclusiones que se puedan ir levantando al respecto.

\section{El investigador frente al expediente}

En términos generales, los primeros usos historiográficos que se hicieron de la fuente judicial, no cuestionaron el potencial informativo que ofrecía, volcándose con confianza a la búsqueda de los fenómenos sociales y culturales que sus fojas corroídas habrían permitido reconstruir. Pueden considerarse, sobre todo, los trabajos de Edward P. Thompson. El historiador argentino Darío Barriera (2013, p. 359) ha expuesto los lineamientos de esta discusión y las respectivas referencias bibliográficas ligadas al "redescubrimiento de las fuentes judiciales". En esta línea coincide también la primera micro-historia italiana, de la mano de Carlo Ginzburg y de Giovanni Levi, quienes confiaron en la capacidad de las fuentes judiciales de transmitir prístinamente los fenómenos culturales y la dinámica de las redes sociales (GALLUCI 2009, p. 14).

Con los influjos post-estructuralistas, el impulso del "giro lingüístico" y la asunción de las premisas de la "deconstrucción" que adoptaron las humanidades y las ciencias sociales desde fines de la década de 1960 (AGUIRRE 2006, p. 89 y ss.) las investigaciones debieron reconsiderar el valor informativo directo de las fuentes judiciales, como así mismo, el quehacer historiográfico en su integridad. Desde entonces, la pregunta por la veracidad de los testimonios que conformaban la hebra fina de los expedientes, se tornó en una parada obligatoria antes del abordaje de su contenido (BURKE 1978). En este sentido, jugaron un papel relevante los trabajos de las historiadoras Arlette Farge (1991) y Natalie Zemon Davis (1987), quienes realizaron un ejercicio heurístico sobre las narrativas presentes en los testimonios y en las construcciones de discursos judiciales verosímiles, como enfoque necesario antes de desechar este material por carecer de verosimilitud. Las formas comunes y reiterativas de tejer los enunciados con tal de persuadir al interlocutor en el juzgado, decían bastante 
sobre los imaginarios y los valores que se consideraban socialmente legítimos en el pasado. Las narrativas de los litigantes e inculpados, se deslizaban desde la forma del documento hacia su contenido.

La historiografía latinoamericana y latinoamericanista que comenzó trabajando con los expedientes, tampoco cuestionó mayormente este tipo de barreras informativas. De acuerdo a la discusión bibliográfica que propuso Tamar Herzog (1995, p. 318), en esta línea podrían inscribirse, por ejemplo, los trabajos de Michael Scardaville, sobre la criminalidad urbana en México tardo colonial, de Susan Socolow, acerca de la criminalidad femenina en Buenos Aires a fines del siglo XVIII y de Francois Giraud, respecto a las modalidades de la violencia social en México en el mismo periodo.

En Chile ocurrió otro tanto. Desde sus orígenes, la historiografía nacional había esperado el transcurrir de un lento proceso de ordenamiento archivístico entre fines del siglo XIX y el primer cuarto del siglo XX. Por ello, la literatura se había concentrado en el acontecimiento emanado de la dispersa documentación oficial disponible (ENCINA 1949). La discusión estaba condicionada a orientarse hacia las gestas militares heroicas, a los prohombres de la construcción del Estado republicano y a las familias asociadas a estas figuras. La ausencia de las grandes mayorías en el relato historiográfico sólo fue suplida por la emergencia de la historiografía marxista desde mediados del siglo XX (GREZ 2005), aunque los sectores sociales que merecieron la atención sólo fueron aquellos inscritos en el devenir de la proletarización progresiva. Sólo las figuras de Mario Góngora desde la medianía del siglo XX y de Álvaro Jara, Rolando Mellafe y Gabriel Salazar, desde entonces hasta la década de 1980, contribuyeron, junto a otros y otras, a problematizar históricamente la existencia de sectores sociales de los que no se sabía nada hasta el momento, como los inquilinos, vagabundos, afrodescendientes, labradores y peones.

Por lo anterior, la historiografía nacional de las últimas décadas ha interpretado la disponibilidad de la fuente judicial como una veta inexplorada para recuperar las vidas y conciencias de vastos sectores de la población marginados de la producción académica. El entusiasmo nacido de la convicción de estar frente a un material sub-utilizado por el oficio y de la prisa por acceder a sus hallazgos, opacó los cuestionamientos críticos que ameritaba este tipo de insumos. Algunos estudios que se levantaron y lo siguen haciendo desde las fuentes judiciales y que no han enfrentado las preguntas respecto a su naturaleza fragmentaria y mediada, han sido los de Jaime Valenzuela (1991), Holdenis Casanova (1994), Rolando Mellafe (1994), Eduardo Cavieres (1998), René Salinas M. (1998; 2000) Claudia Arancibia, Tomás Cornejo y Carolina González (2003), Leonardo León (2005), Mauricio Rojas (2008), Verónica Undurraga (2012) Ivette Lozoya (2014), entre los que han tenido mayor influencia.

Así entonces, la historiografía en Chile que ha apoyado sus investigaciones sobre estos expedientes, parece presa en los vericuetos de un nudo gordiano. En los casos en que se ha visualizado la utilidad de los testimonios presentes en sus fojas, se han soslayado las preguntas elementales respecto a las condiciones de posibilidad de tales enunciados y a las distancias entre hechos y versiones de 
hechos. Por el contrario, el sometimiento de los discursos judiciales a una crítica de-constructiva tiende a arrastrar la investigación hacia un pesimismo heurístico, concluyendo la inutilidad del documento para decir algo certero sobre el pasado. Todo indica que una salida productiva al respecto viene construyéndose desde la posibilidad de ejercer una "lectura a contrapelo" sobre el archivo.

La aplicación del método asociado a una "lectura a contrapelo" de la documentación de archivo, entrega las herramientas para trascender la información explícita, comprender las condiciones de producción que le dieron vida material y, sobre todo, develar las correlaciones de fuerza que generaron la mediación escritural. Una serie de autores han propuesto el método de la "lectura a contrapelo" de los documentos, como ejercicio de búsqueda de las relaciones de poder que sostuvieron su construcción. El pionero en este sentido y que acuñó el término fue Walter Benjamin (AGUIRRE 2015, p. 41 y ss.) Este ejercicio crítico sobre las condiciones de producción de cualquier constructo cultural (entendidos por tanto como "textos" que podían someterse a la crítica sobre las dinámicas de su generación), recibió nuevos aires tras las propuestas etnográficas de Cliford Geertz, en la década de 1970 (TERRADAS i SABORIT 2001, p. 188). Particularmente para el caso de propuestas de "lectura a contrapelo" en las fuentes judiciales, sirvieron los subsidios post-marxistas y post-coloniales que el Grupo de Estudios Subalternos le brindó a la "Historia desde abajo", desde mediados de la década de 1980, escudriñando la serie de estratos de dominación y hegemonía que operaron en la construcción de la fuente y en la invisibilización de la "voluntad del sujeto" (GUHA 1988, p. 45-86; 1998, p. 39-40).

La aproximación a los testimonios en los expedientes de archivo, no radicaría en un ejercicio de extracción directa del contenido de sus relatos, sino, en cambio, del análisis respecto a la trama compleja de fabricación documental. Desde entonces, el proceso de construcción de la fuente debía ser entendido como producto de relaciones desiguales de fuerza, donde el sujeto histórico, pese a encontrarse en situación de desventaja, pudo maniobrar y deslizar su voluntad por los intersticios del poder. Las relaciones de fuerza que antecedieron y sostuvieron el proceso de escritura oficial en el pasado, habrían permitido todo un "arte de la resistencia" de estos actores sociales (SCOTT 2000). La historiografía latinoamericana y latinoamericanista se apoyó en estos marcos teoréticos para enfrentar el estudio de la "construcción negociada" del poder y para el análisis de las "culturas políticas" de la plebe. Hasta hoy, son de referencia obligada los trabajos de Eric Van Young, Gilbert Joseph, Daniel Nugent, Florencia Mallon, Luis Miguel Glave, Ricardo Salvatore, entre otros, discusión que sintetizó con acierto Raúl O. Fradkin (2008, p. 27, 29 y 56). También resultan pertinentes los aportes de Inés Ortiz Yam (2005) y de Di Meglio (2008). ${ }^{4}$

Tras la consideración de estos antecedentes, en la historiografía chilena comenzaron a surgir estudios que tenían como centro la problematización del

\footnotetext{
${ }^{4}$ De modo más directo, la "historia de la justicia" en la región venía centrando su atención en los "usos sociales" que los sujetos en situación de dominación -indios, "castas", afrodescendientes, mujeres, pobres urbanos, etc.- hicieron de la disponibilidad judicial en busca de mantener o mejorar sus posiciones (STERN 1982; BORAH 1985; REIS 1986; AGUIRRE 1993; DÍAZ 2000; OWENSBY 2011).
} 
documento judicial con tal de visualizar los perfiles de "conciencias subalternas". La hermenéutica sobre las narrativas de los testimonios y los ejercicios de "lecturas a contrapelo", permitieron la emergencia de monografías que se enfocaban crecientemente en las estructuras de discursos persuasivos de los litigantes e inculpados, como tácticas integrantes de un "saber hacer" en situación judicial (TUOZZO 1996; ROJAS 1999; FERNÁNDEZ 2007; BRANGIER 2012b). Esta presunción metodológica llevó a centrar el análisis en los elementos axiológicos que conformaban tales versiones argumentadas y a estudiar los intereses que constituían su norte (CORNEJO 2007).

El salto desde el foco en las estructuras narrativas y en las tácticas persuasivas, hacia una "lectura a contrapelo" que desmonte las etapas y tensiones sociales incrustadas en la fabricación del documento, resulta aún una tarea pendiente. Los trabajos de las historiadoras María Eugenia Albornoz (2006; 2011; 2012) y Aude Argouse $(2013 ;$ 2014), han permitido pensar la documentación judicial expedientes judiciales coloniales y los cuadernos de escribanos- como constructos generados a raíz de situaciones específicas de poder, de encuentros dialógicos y con una función política performativa de la realidad.

La doble fragmentariedad constitutiva de los juicios criminales iniciados de parte, presentes en los repositorios del $\mathrm{ANH}$, obligan a esquivar la tentación de reconocer su contenido como versiones diáfanas de realidades externas al juicio. En cambio, la deconstrucción de su proceso tenso de fabricación, como estrategia metodológica, entrega pistas sobre los juegos tensos en que se sostuvieron las sociedades en el pasado y respecto a las oportunidades sociales de participar en el proceso de escritura judicial, y por tanto, de erección de la misma institucionalidad judicial. Particularmente para los estudios centrados en el siglo XIX, el enfoque permite atisbar los modos en que los sujetos sociales supieron participar del sendero frágil y reversible que llevó a la construcción de Estado, como además, en el delineamiento de un poder judicial corporizado y localizado en su entorno más inmediato. ${ }^{5}$

Por otro lado, queda pendiente la tarea por abordar los expedientes, considerando el gesto de mediación que les resultó inherente y del que no pudieron escapar, pues implicaba la condición misma de su existencia material. En este sentido, la apertura hacia los enfoques culturalistas que asumió la historiografía latinoamericana desde la década de 1990 (MALERBA 2010, p. 93) ha abonado el terreno para recoger la perspectiva socialmente negociada de la noción de "cultura" que ha predominado desde entonces. La "nueva" Historia Cultural ha comprendido a la cultura como conjunto de significados, como repositorio simbólico común y aprovechable por los distintos estratos sociales. Bajo este prisma, autores como Hayden White (1974) o Peter Burke (1978)

\footnotetext{
${ }^{5}$ Los avances que podrían adelantarse bajo esta óptica, contribuirían a la erosión del antiguo lugar común de los estudios sobre el siglo XIX, respecto a la eficiencia en la construcción y consolidación prematura de un estado nacional. Pese a la crítica levantada a esta perspectiva (SALAZAR 2005), los estudios no han abordado al Estado como objeto de estudio y por tanto, como puntualizó el antropólogo e historiador argentino Germán Soprano (2010) se sabe muy poco sobre las fragilidades y porosidades de las instituciones oficiales -como la justicia- toda vez que las investigaciones en Chile, centradas en el mundo social, han dado por sentado su capacidad de intervenir la sociedad.
} 
tempranamente cuestionaron la distinción de una "alta" y una "baja" cultura. El modelo, por cierto, no excluye en absoluto la centralidad del conflicto y la lucha social entre los sujetos que hicieron uso de este conjunto de significados y símbolos. Por el contrario, el enfoque enriqueció la teoría del conflicto y de la construcción de hegemonía, al brindar pistas respecto al modo en que los actores escrutan los elementos del campo cultural que le pueden ser de más provecho, para posicionarse de mejor modo en el plexo de las tensiones sociales. Como propuso el historiador británico Edward Thompson (1995, p. 102), uno de los primeros exploradores en esta perspectiva, "la contienda simbólica adquiere su sentido sólo dentro de un equilibrio determinado de relaciones sociales".

Los influjos de esta "Nueva" Historia Cultural y de su aclimatación a las historiografías latinoamericanas, han dado pie para una re-lectura de la mediación escritural constitutiva del expediente. El guante está arrojado para que las investigaciones examinen la documentación de este tipo como artefactos culturales, como producto de las interacciones entre sujetos en contienda y en posición desigual, aunque compartiendo unos mismos lenguajes y códigos que, posteriormente fueron apropiados en pos de sus propias expectativas e intereses. En este sentido, no conviene descartar el valor informativo de los testimonios de los litigantes o imputados sólo porque fueron transcritos por agentes de los juzgados o pasaron por el tamiz de sus "escuchas" tergiversadoras. El escrutinio de la transversalidad social de los lenguajes desplegados en los estrados, suaviza la violencia con la que se pensaba el ejercicio de la escritura del expediente y permite, en cambio, examinar los valores, representaciones e imaginarios que compartían los justiciables con los agentes de la escritura judicial. Los códigos axiológicos, lenguajes y legitimidades socialmente compartidos y apropiados en la justicia criminal del Chile del siglo XIX instan a analizar la traducción del escribano, como una práctica inserta en estos imaginarios sociales de los que también formaban parte los sujetos deponentes.

La historiografía en Chile no ha echado mano del enfoque de los lenguajes comunes para enfrentar la condición mediada de los testimonios judiciales. Pese a que a mediados del siglo XX, el historiador Mario Góngora (1951) había sentado las bases para una lectura de la construcción de todo documento oficial, bajo el prisma de las "convicciones jurídicas" socialmente compartidas, el legado no fue recogido sistemáticamente. De todos modos, en los últimos 20 años ha habido una incorporación de enfoques culturalistas de orientación deconstructiva que ha permeado al campo historiográfico nacional y particularmente a los estudios centrados en las fuentes judiciales. Uno de los factores que explican este giro ha sido la fundación y desarrollo de centros de estudios culturales alojados en el seno de los principales nichos académicos de investigación humanística del país. ${ }^{6}$ El proceso debe ser complementado con el impulso que la historiografía latinoamericana sobre la justicia ha irrogado sobre los círculos nacionales de

\footnotetext{
${ }_{6}$ Cabe destacar el Centro de Estudios Culturales Latinoamericanos y el Centro de Estudios de Género y Cultura de América Latina, ambos de la Facultad de Filosofía y Humanidades de la Universidad de Chile, cuyo desarrollo ha estado en curso desde la década de 1990. En esta línea, también ha jugado un papel importante el Instituto de Estudios Avanzados de la Universidad de Santiago de Chile, desde la misma década.
} 
discusión. El influjo motivó un interés que ha llevado al despliegue creciente de la investigación al respecto y al nacimiento, el año 2011, del Grupo de Estudios Historia y Justicia y el año 2013, de la Revista Historia y Justicia, gestionada por el mismo colectivo.

Precisamente en el seno del Grupo de Estudios Historia y Justicia se ha aventurado un diálogo interdisciplinario que ha permitido lecturas deconstructivas sobre la fuente judicial. ${ }^{7}$ El producto de la discusión ha sido la emergencia de trabajos que han escrutado los lenguajes comunes presentes en la documentación. Por ejemplo, destacan los de Carolina González (2012; 2012b) que han puesto el acento en los agentes de los juzgados coloniales encargados de vehiculizar socialmente todo un campo de "saber hacer" en justicia. También han jugado un papel significativo los avances de María Eugenia Albornoz (2007; 2014), respecto a los mismos saberes desplegados por sujetos - principalmente mujeres- en situaciones de injuria y reconocidos por los jueces. Víctor Brangier, últimamente, en co-autoría con Darío Barriera (2015), ha escarbado en la manifestación judicial de estos lenguajes comunes compartidos tensamente por los justiciables, los jueces y los agentes encargados de la escritura de los testimonios. Sin embargo, se trata de esfuerzos en desarrollo que requieren la puesta en común de problemas, registros y experiencias de archivo. El desafío de la mediación escritural representa todavía un tópico que debe situarse en el centro de la discusión de aquel trabajo historiográfico que construye sus indagaciones desde los expedientes judiciales del ANH.

\section{Consideraciones finales}

Tras el escrutinio de los factores que confluyeron en la escritura de los expedientes judiciales criminales en el siglo XIX en Chile, ha podido asentarse su doble carácter fragmentario (como retazos de juicios, los que a su vez reflejaron estelas de conflictos sociales) y la necesaria mediación escritural existente entre voz testimonial y documento. El examen ha permitido evaluar el modo en que la historiografía chilena, que ha venido trabajando con intensidad sobre este material durante las últimas décadas, ha problematizado estas aristas y ha apropiado metodologías surgidas en otras latitudes tendientes a constituir a la fuente judicial como objeto de estudio. El artículo ha dado pistas para proyectar el horizonte de desafíos hermenéuticos por abordar, antes de continuar con un ejercicio de archivo acrítico respecto al testimonio en situación de justicia. En este sentido, el análisis de enfoques que apunten a transitar al revés las fases históricas que convergieron para posibilitar la existencia material del expediente, la indagación sobre las tensiones sociales y políticas que insuflaron vida al conflicto social, al juicio y a la escritura de los testimonios, en una palabra, las "lecturas a contrapelo" sobre esta materia prima, permitirían abrir nuevas preguntas que sitúen en el centro de la cuestión al archivo judicial. El abordaje documental desde estas claves propiciará el desplazamiento del expediente 
desde su condición de fuente primaria a objeto de estudio, en el diseño de investigación. De modo análogo, la lectura de los lenguajes, las legitimidades y las retóricas persuasivas de los justiciables, por un lado $y$, por otro, las escuchas y escrituras de escribanos y jueces, desde un prisma "culturalista", permitiría situar la atención en los lenguajes y códigos socialmente compartidos y tensamente apropiados, como condición de posibilidad del conflicto, del juicio y del expediente. En este sentido, la escritura del documento ya no se concibe como un obstáculo para acceder a las conciencias y voces genuinas de los deponentes, sino como una ventana para comprender las interacciones de esas conciencias dentro de un campo cultural en permanente desgarro por los distintos intereses en juego.

\section{Referencias bibliográficas}

AGÜERO, Alejandro. Castigar y perdonar cuando conviene a la república:

La justicia penal de Córdoba del Tucumán, siglos XVII y XVIII. Madrid: Centro de Estudios Políticos y Constitucionales, 2008.

AGUIRRE, Carlos. Agentes de su propia libertad: Los esclavos de Lima y la desintegración de la esclavitud, 1821-1854. Lima: Pontificia Universidad Católica del Perú, 1993.

AGUIRRE, Carlos. La escuela de los Annales: Ayer, Hoy, Mañana. Rosario: Prohistoria, 2006.

Retratos para la Historia: Ensayos de biografía intelectual sobre pensadores del siglo XX. Rosario: Prohistoria; Universidad Nacional de Rosario, 2015.

ALBORNOZ, María E. Seguir un delito a lo largo de los siglos: interrogaciones al cuerpo documental de pleitos por injuria en Chile. Revista de Historia Social y de las Mentalidades, v. 10, n. 2, p. 195-225, 2006.

El mandato de 'silencio perpetuo'. Existencia, escritura y olvido de conflictos cotidianos (Chile, 1720-1840). In: CORNEJO, T.; GONZÁLEZ C. (eds.). Justicia, poder y sociedad en Chile: recorridos históricos. Santiago: Universidad Diego Portales, 2007, p. 17-55.

.El Archivo Secreto de la Real Audiencia de Chile (1780-1809): ¿Proteger la memoria de la injuria o censurar prácticas díscolas de poder local? In: BERNABEÚ, S.; LANGUE, F. (coords.). Fronteras y sensibilidades en las Américas. Madrid: Doce Calles, 2011, p. 99-124.

. La temporalidad, las ausencias presentes y los motivos. Conflictos, justicias y género en una villa recién fundada: San Felipe, Chile, 1747. Nuevo Mundo Mundos Nuevos, n. 12, 2012.

- Casos de corte y privilegios de pobreza: lenguajes jurídicos coloniales y republicanos para el rescate de derechos especiales en el momento de litigar por injurias. Chile, 1700-1874. Signos Históricos, n. 32, p. 58-85, 2014. 
ANGUITA, Ricardo. Leyes promulgadas en Chile desde 1810 hasta el $1^{\circ}$ de junio de 1913. Santiago: Imprenta Litografía y Encuadernación Barcelona, 1913. t. 1.

ARANCIBIA, C. ; CORNEJO, T. ; GONZÁLEZ C. Pena de muerte en Chile Colonial: Cinco casos de homicidio de la Real Audiencia, estudio preliminar y transcripción. Santiago: Universidad de Chile; Centro de Investigaciones Diego Barros Arana; RIL, 2003.

ARCHIVO NACIONAL HISTÓRICO. Guía de Fondos del Archivo Nacional Histórico: Instituciones coloniales y republicanas. Santiago: Dirección de Bibliotecas, Archivos y Museos; Centro de Investigación Diego Barros Arana, 2009.

ARGOUSE, Aude. De los momentos del delito al monumento archivístico: el expediente criminal del oidor león. Santiago de Chile, 1673-1675. Historia y Justicia, n. 1, p. 1-27, 2013.

- Testimonios voluntarios e involuntarios de la vida cotidiana y de la justicia en Valparaíso. Los primeros registros de escritura pública, entre cuadernos y pruebas. In: CORREA, María J. (coord.). Justicia y vida cotidiana en Valparaíso: Siglos XVII-XX. Santiago: Acto, 2014, p. 5994.

BARRIERA, Darío. El equipamiento político del territorio. Del Pago de los Arroyos a la ciudad de Rosario (1725-1852). In: BARRIERA, D. (dir.). Instituciones, Gobierno y Territorio: Rosario, de la Capilla al Municipio (1725-1930). Rosario: ISHIR; CONICET, 2010, p. 17-63.

- Abrir puertas a la tierra: Microanálisis de la construcción de un espacio político. Santa Fe, 1573-1640. Santa Fe: Ministerio de Innovación y Cultura de la Provincia de Santa Fe; Museo Histórico Provincial "Brigadier Estanislao López", 2013.

BOHOSLAVSKY, E.; GODOY, M. (eds.).Construcción estatal, orden oligárquico

y respuestas sociales: Argentina y Chile, 1840-1930. Buenos Aires: Prometeo; Universidad Nacional del General Sarmiento, 2010.

BORAH, Woodrow. El Juzgado General de Indios en la Nueva España. México: Fondo de Cultura Económica, 1985.

BRANGIER, Víctor. 'En la más bastante forma que haya lugar en derecho ante vuestra merced comparezco...'. Entre el 'sujeto social' y el 'subalterno judicial': en torno al valor heurístico de las fuentes judiciales. Análisis de un expediente modelo. Chile, inicios del siglo XIX. Tradición y Saber, $n$. 9, p. 195-223, 2012a.

- Transacciones entre ley y prácticas judiciales locales, en tiempos de codificación. El caso de la Visita Judicial Nacional. Chile, 1848-1849. SudHistoria, n. 5, p. 124-151, 2012b. 
; BARRIERA, Darío. Lenguajes comunes en 'justicias de jueces'. Tratamientos historiográficos y fondos judiciales en Chile y Argentina. Revista de Humanidades, n. 32, p. 227-258, 2015.

BURKE, Peter. Popular Culture in Early Modern Europe. Nueva York: New York University Press, 1978.

CASANOVA, Holdenis. Diablos, brujos y espíritus maléficos: Chillán, un proceso judicial del siglo XVIII. Temuco: Universidad de La Frontera, 1994.

CAVIERES, Eduardo. Faltando a la fe y burlando a la ley. Bígamos y adúlteros en el Chile tradicional. Contribuciones Científicas y Tecnológicas, $n$. 118, p. 137-151, 1998.

CELIS, Nicolás. 'Lo que se hablaba de él y la escandalosa vida que estaba dando al público'. Aproximación a la noción de escándalo a partir de las huellas del rumor en las prácticas de conciliación informal. el caso de don José Tadeo Alquizar por vivir escandalosamente con una mulata. Santiago de Chile 1795. Revista de Historia Social y de las Mentalidades, v. 19, n. 2, p. 105-126, 2015.

CORNEJO, Tomás. Testimonios y testigos: el problema de la fuente. In: CORNEJO, T.; GONZÁLEZ, C. (eds.). Justicia, poder y sociedad en Chile: recorridos históricos. Santiago: Universidad Diego Portales, 2007, p. 241-266.

DAVIS, Natalie Z. Fiction in the Archives: Pardon Tales and their Tellers in Sixteenth-century France. Stanford: Stanford University Press, 1987.

DE ARAUJO, Álvaro. O Código Intentado: lei e justiça na 'economia da imposição' Portugal, finais do século XVIII e início do século XIX. In: BARRAL, M. E.; SILVEIRA, M. (coords.). Historia, poder e instituciones: Diálogo entre Brasil y Argentina.Rosario: Prohistora; Universidad Nacional de Rosario, 2015, p. 126-142.

DE RAMÓN, Armando. La justicia chilena entre 1875 y 1924. Cuadernos de Análisis Jurídico, v. 12, p. 1-59, 1989.

DIAZ, María E. The Virgin, The King, and the royal slaves of El Cobre: Negotiating freedom in colonial Cuba, 1670-1780. Stanford: Stanford University Press, 2000.

DI MEGLIO, Gabriel. Las palabras de Manul. La plebe porteña y la política en los años revolucionarios. In: FRADKIN, R. (ed.). ¿Y el pueblo dónde está? Contribuciones para una historia popular de la revolución de independencia en el Río de la Plata. Buenos Aires: Prometeo, 2008, p. 67-105.

ENCINA, Francisco. Breve bosquejo de la literatura histórica chilena. Atenea, n. 291, p. 27-68, 1949.

ESTADO DE CHILE. Lei de Organizacion i Atribuciones de los Tribunales.

Santiago: Imprenta de la República, 1875. 
FARGE, Arlette. La atracción del archivo. Valencia: Ediciones Alfons El Magnánim; Institució Valenciana D’ Estudis i Investigació, 1991.

FERNÁNDEZ, Marcos. Sangre por sangre: la retórica judicial y la veracidad documental como problema heurístico en las solicitudes de indulto. In: CORNEJO, T. ; GONZÁLEZ C. (eds.). Justicia, poder y sociedad en Chile: recorridos históricos. Santiago: Universidad Diego Portales, 2007, p. 195-223.

FRADKIN, Raúl. Cultura política y acción colectiva en Buenos Aires (18061829): un ejercicio de exploración. In: FRADKIN, R. (ed.). ¿Y el pueblo dónde está? Contribuciones para una historia popular de la revolución de independencia en el Río de la Plata. Buenos Aires: Prometeo, 2008, p. 27-65.

GALLUCI, Lisandro. Las fuentes judiciales y el estudio de los sectores subalternos: Desafíos y posibilidades de su relación en la investigación historiográfica. Ponencia. Segundas Jornadas Nacionales de Historia Social. Córdoba, Argentina, 2009. Disponible en: ww.refa.org.ar/file. php?name=FILE_ediciones1369674443.pdf. Consultado el: 18 ene. 2015.

GARRIGA, Carlos. Orden jurídico y poder político en el Antiguo Régimen. Istor, v. IV, n. 16, p. 13-44, 2004.

GREZ, Sergio. Escribir la historia de los sectores populares ¿con o sin la política incluida? A propósito de dos miradas a la historia social (Chile, siglo XIX). Política, n. 44, p. 17-31, 2005.

GÓNGORA, Mario. El Estado en el Derecho Indiano: Época de Fundación (1492-1570). Santiago: Universitaria, 1951.

GONZÁLEZ, Carolina. El abogado y el procurador de pobres: la representación de esclavos y esclavas a fines de la Colonia y principios de la República. SudHistoria, n. 5, p. 81-98, 2012.

- Las posibilidades del registro judicial para rastrear la recepción de saberes sobre justicia y gobierno. Nuevo Mundo Mundos Nuevos, 2012. Disponible en: http://nuevomundo.revues.org/62418. Consultado el: 29 nov. 2013 b.

GUHA, Ranajit. The Prose of Counter Insurgency. In: GUHA, R.; SPIVAK, G. (eds.) Selected Subaltern Studies. Oxford; New York: Oxford University Press, 1988, 45-86.

.Chandra's Death. In: GUHA, R. (ed.). A Subaltern Studies Reader: 1986-1995. Minneapolis; London: University of Minnesota Press, 1998, p. 34-62.

HERZOG, Tamar. La administración como un fenómeno social: la justicia penal de la ciudad de Quito (1650-1750). Madrid: Centro de Estudios Constitucionales, 1995. 
HESPANHA, Antonio M. De Iustitia a Disciplina. In: La Gracia del Derecho: Economía de la Cultura en la Edad Moderna. Madrid: Centro de Estudios Constitucionales, 1993, p. 203-273.

KAGAN, Richard. Pleitos y pleiteantes en Castilla: 1500-1700. Salamanca: Junta de Castilla y León; Consejería de Cultura y Turismo, 1991.

LEÓN, Leonardo. La Violencia Mestiza y el mito de la Pacificación: 18801900. Santiago: Universidad Arcis, 2005.

LOZOYA, Ivette. Delincuentes, bandoleros y montoneros: Violencia social en el espacio rural chileno (1850-1870). Santiago: LOM, 2014.

MALERBA, Jurandir. La historia en América Latina: Ensayo de crítica historiográfica. Rosario: Prohistoria, 2010.

MANTECÓN, Tomás. Usos de la justicia y arbitraje de los conflictos en el antiguo régimen: experiencias en la monarquía hispánica. Revista de Historia Social y de las Mentalidades, v. 19, n. 2, p. 209-235, 2015.

MELLAFE, Rolando. Interpretación histórico-metodológica de la delincuencia en Chile del siglo XXI. Contribuciones Científicas y Tecnológicas, n.118, p. 21-26, 1994.

MORENO, Daniel. 'Un devorador de su propia especie'. Violencia, justicia y cultura popular en santa rosa de los andes: las formas de la autoridad a los ojos de un peón de oficio matador, Chile 1805. Revista de Historia Social y de las Mentalidades, v. 19, n. 2, p. 127-158, 2015.

MORICONI, M.; BARRIERA, D. Las justicias en Santa Fe del Río de la Plata durante el periodo colonial (ss. XVI-XVIII). In: BARRAL, María E.; SILVEIRA, M. (coords.). Historia, poder e instituciones: Diálogo entre Brasil y Argentina.Rosario: Prohistora; Universidad Nacional de Rosario, 2015, p. 143-165.

ORTIZ, Inés. El Descontento de los Pueblos Yucatecos a Finales del Siglo XX. Una Aproximación a la Percepción de los Milperos Durante el Proceso Privatizador. In: FALCÓN R. (coord.). Culturas de pobreza y resistencia: Estudios de marginados, proscritos y descontentos México, 1804-1910. México: El Colegio de México; Universidad Autónoma de Querétaro, 2005, p. 285-305.

OWENSBY, Brian. Pacto entre rey lejano y súbditos indígenas. Justicia, legalidad y política en Nueva España, siglo XVII. Historia Mexicana, v. 1, n. LXI, p. 59-106, 2011.

REIS, Joao J. Rebeliao escrava no Brasil: historia do levante dos Males (1835). San Pablo: Brasiliense, 1986.

ROJAS. María T. Agresión de hombre, defensa de mujer: Una aproximación a la violencia conyugal y la justicia en el mundo popular. Zona central de Chile 1760-1830. Revista de Historia Social y de las Mentalidades, v. 2, n. 3, p. 89-16, 1999. 
ROJAS, Mauricio. Las Voces de la Justicia: Delito y sociedad en Concepción (1820-1875). Atentados sexuales, pendencias, bigamia, amancebamiento e injurias. Santiago: DIBAM; Centro de Investigaciones Diego Barros Arana, 2008.

SALAZAR, Gabriel. Construcción de Estado en Chile (1800-1837): Democracia de "los "pueblos. Militarismo ciudadano. Golpismo oligárquico. Santiago: Sudamericana, 2005.

SALINAS, René. Espacio doméstico, solidaridades y redes de sociabilidad aldeana en Chile tradicional, 1750-1880. Contribuciones Científicas y Tecnológicas, n. 118, p. 1-19, 1998.

. Violencias sexuales e interpersonales en Chile tradicional. Revista de Historia y de las Mentalidades, n. 4, p 13-49, 2000.

SCOTT, James. Los dominados y el arte de la resistencia: Discursos ocultos. México D.F.: Era, 2000.

SOPRANO, Germán. Estados nacionales, regiones y fronteras en la producción de una historia social del orden estatal en América Latina. In: BOHOSLAVSKY, E.; GODOY, M. (eds.). Construcción estatal, orden oligárquico y respuestas sociales: Argentina y Chile, 1840-1930. Buenos Aires: Prometeo; Universidad Nacional del General Sarmiento, 2010, p. 323332.

112 StABili, María R. Jueces y justicia en el Chile liberal. In: CARMAGNANI, M. (coord.). Constitucionalismo y orden liberal: América Latina, 18501920. Turín: Otto Editore, 2000, p. 227-258.

STERN, Steve. Perú's Indian Peoples and the Challenge of Spanish Conquest: Huamanga to 1640. Madison: University of Wisconsin Press, 1982.

TERRADAS I SABORIT, Ignasi. La Historia de las Estructuras y la Historia de la Vida. Reflexiones sobre las Formas de Relacionar la Historia Local y la Historia General. In: FERNÁNDEZ, S. ; DALLA CORTE, G. (comps.). Lugares para la historia: Espacio, historia regional e historia local en los estudios contemporáneos. Rosario: Universidad Nacional de Rosario Editora, 2001, p. 179-308.

THOMPSON, Edward. Costumbres en Común. Barcelona: Crítica, 1995.

TUOZZO, María C. Apuntes metodológicos: el problema de la verosimilitud en el estudio de los sumarios criminales. Actas Americanas, n.4, p. 5-17, 1996.

UNDURRAGA, Verónica. Los rostros del honor: Normas culturales y estrategias de promoción social en Chile colonial, siglo XVIII. Santiago: Editorial Universitaria; DIBAM; Centro de Investigaciones Diego Barros Arana, 2012. 
Presentación Dossier Formas de conciliación y mecanismos informales de resolución de conflictos en Chile siglos XVII a XIX. Revista de Historia Social y de las Mentalidades, v. 19, n. 2, p. 1-2, 2015.

VALENZUELA, Jaime. Bandidaje Rural en Chile Central: Curicó 1850-1900. Santiago: DIBAM, 1991.

WHITE, Hayden. Structuralism and Popular Culture. Journal of Popular Culture, n. 7, p. 759-775, 1974. 